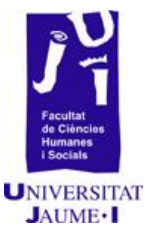

\title{
Elisabeth Bennet y Bridget Jones: del protofeminismo al postfeminismo
}

Dori Valero-Valero avalero@uji.es dori2v@yahoo.es 
Las teorías feministas se han introducido en la literatura de ficción facilitando modelos alternativos a las lectoras. Las heroínas llevan a cabo una tarea de "resistencia feminista», y tomaremos los siguientes ejemplos: Elizabeth Bennet, Orgullo y prejuicio (1813) y Bridget Jones, El diario de Bridget Jones (1999).

Jane Austen construye protagonistas femeninas que responden a las estructuras patriarcales de la época. Elizabeth Bennet destaca, en este sentido, por su inteligencia, capacidad de argumentación y defensa de sus principios. Es decir, lo contrario al canon de mujer de principios del siglo XIX. Austen es consciente, así lo expone en diferentes momentos de la narración, de que Elizabeth Bennet es capaz de presentarse como una "mujer distinta» porque ha sido instruida. Esto nos lleva directamente a la teoría protofeminista de Mary Wollstonecraft (1790), que reivindica la formación de las mujeres como un aspecto fundamental para adquirir autonomía personal y social.

Bridget Jones es la otra protagonista a través de las que rastreamos la ruptura con los roles de las sociedades patriarcales. Icono de un nuevo tipo de literatura, la chick lit (literatura para chicas), Jones presenta la contradictoria situación en la que se encuentran muchas mujeres en la actualidad. Por un lado, debe enfrentarse al peso de la tradición y las expectativas sociales que incluyen el matrimonio heterosexual; por otro, al diseño y desarrollo de su propio proyecto vital, un intento constante de empoderamiento que choca con el entorno. El feminismo de este personaje siempre se presenta como controvertido, a pesar de tratar muchos de los temas clásicos del feminismo: la toma de conciencia sobre su cuerpo, su vida sexual, su independencia económica... La identificación que muchas lectoras asumen con el personaje es lo que capacita a éstas para asumir una identidad propia, no siempre ajustada a los estereotipos tradicionales.

Palabras clave: protofeminismo, postfeminismo, feminismo, chick lit, Elisabeth Bennet, Bridget Jones, Jane Austen, Helen Fielding, matrimonio, autonomía personal, y autonomía social.

\section{Introducción}

La literatura nos permite rastrear las características de una sociedad. Incluso los relatos de ciencia ficción nos ayudan a descubrir en qué tipo de sociedad vive el autor o la autora. Pensemos, por ejemplo, en George Orwell (1903-1950) y sus dos novelas emblemáticas: Animal Farm (Rebelión en la granja, 1945) y 1984 (1949). Ambas novelas plantean una clara crítica a los totalitarismos que habían estado arrasando Europa antes y durante la Segunda Guerra Mundial (1939-1945). Si las leemos con atención podemos descubrir qué pasó en Alemania y otros países de 
su entorno en esos años: un estricto control social. Durante siglos, cuando los libros eran el único medio de comunicación "de masas» que existía, los lectores y lectoras encontraban en estos las ideologías, las creencias, las modas, los usos y las costumbres que debían ser aprehendidos e interiorizados por los individuos de una sociedad.

En este artículo nos proponemos desvelar las características socioculturales de dos periodos concretos de la historia, principios del siglo XIX y finales del siglo XX. Doscientos años en los que se han producido cambios sociales de más calado que en los dos mil años anteriores. Pero no todos los miembros y colectivos que componen nuestras sociedades han tenido las mismas oportunidades. Los grupos minorizados se han visto obligados a trabajar más duro, han encontrado más obstáculos, han accedido más tarde $y$, en algunos casos, todavía no han alcanzado los mismos derechos que los grupos que ostentan el poder. Las mujeres, históricamente, han sufrido este retraso en el acceso a los derechos fundamentales. Pero se han esforzado en subvertir su situación de sumisión e indefensión. Al principio de forma poco organizada. Eran mujeres que a título personal conseguían saltarse las normas establecidas y romper con las costumbres y los hábitos de las sociedades patriarcales. Poco a poco, la conciencia de las mujeres como colectivo fue afianzándose, lo que supuso que se organizaran en grupos para demandar sus derechos, primero, y para teorizar sobre su situación, necesidades, deseos, posición en la sociedad, capacidades... Más tarde, llegó la teoría feminista.

Pero centrémonos en cómo esto se manifiesta en los relatos que vamos a analizar. Situémonos en un contexto sin medios de comunicación de masas audiovisuales, antes de la primera mitad del siglo XX. Los estereotipos de mujer que surgen en la literatura se convierten así en primordiales a la hora de educar a las jóvenes. Ensayos como La perfecta casada (1583), de Fray Luis de León, explican la conducta correcta de las mujeres. Pero los relatos de ficción también ponen su granito de arena en el imaginario colectivo. La Celestina (1499) es un inventario de los peligros que acechan a las jóvenes cuando se dejan atrapar por malos consejeros. Todo ello en un contexto en el que el acceso a la literatura para las mujeres era muy difícil. La sociedad patriarcal, consciente de la capacidad formadora y de construcción del imaginario que comentábamos anteriormente, veía la literatura como una amenaza que favorece la adquisición de una mentalidad crítica. Así, el férreo control de las lecturas, sobre todo de las jóvenes, y la dirección hacia un tipo concreto de literatura permite mantener el sistema de privilegios $y$ desigualdades en el que se cimenta el patriarcado. A pesar de ello, las mujeres sienten una atracción especial por la lectura y consiguen acceso a los diferentes textos, incluso los vetados. Karl G. Bauer (1791) advierte sobre las consecuencias perniciosas de la lectura.

Porque la mujer que lee conquista no sólo un espacio de libertad al que sólo ella tiene acceso, sino que consigue al mismo tiempo un sentimiento de autoestima que la hace independiente. Por otra parte, ella se forja su propia visión del 
mundo, una imagen que no necesariamente coincide con la que le han transmitido sus ascendientes y la tradición, ni tampoco con la del hombre. Pese a todo esto está todavía lejos de significar la emancipación femenina de la tutela patriarcal, permite de todos modos ver la puerta abierta al camino que conduce la libertad (Stephan: 2006, 28).

En la actualidad, podría decirse que la mayoría de las mujeres en las sociedades occidentales pueden leer cualquier cosa que deseen. Sin embargo, los libros siguen construyendo la imagen de las mujeres a la medida de los tiempos y no cabe duda que, a pesar de todas las dificultades, el mercado editorial, sabedor de la voracidad lectora de las mujeres, ha buscado géneros literarios que les interesaran. Esta visión general de los modelos de mujer que desde la literatura se sancionan como aceptables nos deja muchas preguntas por responder. Algunas de las cuestiones intentaremos resolverlas en las siguientes páginas.

\section{Objetivos}

La hipótesis central de nuestro trabajo es que las heroínas de las novelas del siglo XIX son ejemplos de resistencia feminista sin saberlo, del mismo modo que los personajes femeninos actuales, de la chick lit (literatura para chicas), trabajan por conservar los derechos al mismo tiempo que reivindican su independencia y su derecho de elección. El objetivo general del trabajo es:

- Responder a la cuestión de si las teorías feministas se han introducido también en la literatura de ficción facilitando modelos alternativos a las mujeres.

- Los objetivos específicos, por otra parte, son:

- Analizar los estereotipos que aparecen en Orgullo y prejuicio (Jane Austen, 1813 [2009]) y El diario de Bridget Jones (Helen Fielding, 1996 [1999]).

- Comparar los estereotipos de ambos relatos y comprobar si ha existido evolución entre ellos.

- Desvelar qué aspectos de la teoría feminista aparecen en la novela. Tanto elementos del protofeminismo como del feminismo actual (postfeminismo).

\section{Material y método}

Hemos elegido una novela fundamental de la literatura universal, y de la literatura escrita por mujeres, cuya trama central narra las circunstancias y los anhelos de una joven aristócrata de principios del XIX, Orgullo y prejuicio (Jane Austen, 1813 [2009]) y un relato contemporáneo, El diario de Bridget Jones (Helen Fielding, 1996 [1999]), que al publicarse inauguró el género literario de la chick lit. Ambas novelas presentan muchas semejanzas, la propia Fielding reconoce: 
«Actually, I just stole the plot from Pride and Prejudice [Robé la trama de Orgullo y prejuicio]». (People.com, 1999) De ahí la oportunidad de comparar ambos textos. En primer lugar, hemos analizado por separado los arquetipos de cada una de las novelas y llevado a cabo una comparación de ambas. Después, hemos rastreado los valores "femeninos» de estos arquetipos y fundamentado una consideración positiva o negativa sobre los mismos utilizando las teorías de las feministas de su época.

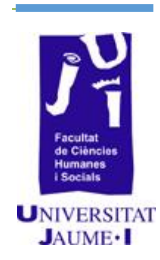

\title{
V. Iniciando el camino de la reivindicación
}

Victoria Sau define el feminismo como:

\begin{abstract}
Un movimiento social y político que se inicia a finales del siglo XVIII -aunque sin adoptar todavía esta denominación- y que supone la toma de conciencia de las mujeres como grupo colectivo humano, de la opresión, dominación, y explotación de que han sido y son sus distintas fases históricas de modelo de producción, lo cual las mueve a la acción para la liberación de su sexo con todas las transformaciones de la sociedad que aquella requiera (Sau, 1981: 121).
\end{abstract}

Aunque es complicado poner una fecha al inicio del feminismo, podemos considerar que todas las acciones llevadas a cabo por las mujeres para subvertir el orden social patriarcal en busca de una igualdad de derechos y de capacidad de decisión pueden ser consideradas el inicio del movimiento. Desde los cuadernos de agravios que incluso antes de la Revolución Francesa se escribían hasta la quema de sujetadores de los sesenta y setenta o la defensa de la aprobación de la Ley del aborto que se ha producido recientemente en el estado español.

Para desarrollar nuestra tesis atenderemos a la tradición anglosajona que reconoce a Mary Wollstonecraft como iniciadora del feminismo, al ser la primera que deja sus reflexiones por escrito de una manera sistemática. Vindicación de los derechos de la mujer (1791) es una extraordinaria guía desde la que comenzar a reclamar derechos para las mujeres. En el texto expone que las mujeres no son inferiores a los hombres, sino que no tienen acceso a la educación, lo que les niega las herramientas suficientes para competir en igualdad de condiciones con los varones. Para Wollstonecraft no habría diferencia en el modo de responder a las mismas situaciones si a las mujeres se les ofreciera también una educación racional. Enumeremos telegráficamente los aspectos que trata la autora británica y que aplicaremos a Orgullo y prejuicio (1813 [2009]), nuestro objeto de estudio.

La diferencia en la educación que reciben en función del sexo hombres y mujeres crea individuos débiles (las mujeres) porque las instruyen en la sumisión y la dependencia. Así, difícilmente se pueden encontrar compañeros iguales en la racionalidad que les permita convivir el libertad (que para Wollstonecraft significa igualdad y con capacidad de elección). 
La belleza es considerada la única virtud femenina, lo que debilita la posición social de las mujeres que no son colocadas en el plano racional en el que se mueven los varones. Ante esta situación, las mujeres quedan fuera del derecho de toma de decisiones con la excusa de que no están capacitadas. La negligente educación es la que les impediría a las mujeres del XVIII adquirir esta capacidad.

Por otro lado, las mujeres viven en un espacio muy reducido (división sexual del trabajo). El espacio doméstico está, siempre ocupado por personas, lo que dificulta el desarrollo del pensamiento femenino. Virginia Woolf casi dos siglos más tarde continúa reivindicando Una habitación propia (1929), ya que el problema de la intimidad donde desarrollarse como ser humano.

La institución organizadora de la sociedad por antonomasia es la familia. En ella se fomenta la formación deficiente, la dependencia... Las mujeres son empujadas al matrimonio. Aquellas que no consiguen el estatus de mujer casada dependen de sus tutores de por vida. De esta manera, la familia se convierte en un espacio de fuerte competencia para hacerse con el favor de quienes tienen los medios de subsistencia que son los hombres. La belleza y la capacidad de gestión de lo doméstico son los méritos que exhiben para obtener esa posición de privilegio.

Esta situación está respaldada por la costumbre social, pero también por la legalidad vigente en el XVIII que obstaculiza el avance de las mujeres en la sociedad civil. Por ejemplo, la reglamentación sobre las uniones matrimoniales a juicio de la autora señala:

Las leyes concernientes a la mujer [...] hacen del hombre y su esposa una unidad absurda y, luego, mediante el paso sencillo de considerarlo sólo a él como responsable, se la reduce a ella a un mero cero a la izquierda. (Wollstonecraft, 1791 [1994]: 318).

La escritora británica no se conforma con repasar las situaciones de desigualdad entre mujeres y hombres intenta plantear soluciones que faciliten la superación de este escenario y lo sustituyan por uno más equitativo. De esta manera, las mujeres adquirirían mejores posibilidades de trabajo. El esfuerzo por conseguir un trabajo le ayudaría a adquirir la dignidad que en una vida acomodada no se encuentra. Podría ir más allá del espacio doméstico y el cuidado de la familia.

Las responsabilidades más sagradas, entonces, se consideran sinecuras porque se procuraron mediante interés y sólo se buscaron para que permitieran a un hombre mantener una buena compañía. Todas las mujeres, en particular, quieren ser señoras, lo que significa simplemente no tener nada que hacer, más que ir con indiferencia a donde poco les importa, porque no pueden decir nada. (Wollstonecraft, 1791 [1994]: 322). Aunque se ha acusado a la escritora británica de intentar destruir la institución familiar, lo cierto es que cuando aboga por una mayor educación de las mujeres está razonando que una mujer instruida podría ser mejor esposa y madre.

Para organizar una familia, para educar a los hijos, se requiere de modo especial entendiendo, en un sentido sencillo: fortaleza de cuerpo y 
alma [...] la razón absolutamente necesaria para que la mujer sea capaz de cumplir todo deber con propiedad, y debe repetir que sensibilidad no es razón. (Wollstonecraft, 1791 [1994]: 194-195)

Las mujeres no son inferiores por naturaleza sino que la educación recibida alejada de la razón, las convierte en seres incompletos. Una educación racional sería beneficiosa para la sociedad, pues las convertiría en «compañeras» de sus maridos y en madres más capacitadas. Wollstonecraft habla de obtener los mismos derechos desde una perspectiva de los derechos naturales, una igualdad basada en un principio de moral natural por la cual todos son iguales como miembros del reino de Dios sujeto a estas leyes naturales. En realidad, no cuestiona las diferencias físicas, que son evidentes, sino cómo la educación que reciben las mujeres agudiza las diferencias en las capacidades aprendidas.

\section{Austen y Wollstonecraft: almas rebeldes que caminan juntas}

Mary Wollstonecraft (1759-1797) y Jane Austen (1775-1817) no son contemporáneas, pero sus tesis feministas tienen mucho en común, mientras sus vidas personales son de lo más dispares. La primera escandalizó en varias ocasiones a sus coetáneos con amantes y relaciones afectivas con mujeres. Austen, por su parte, siempre siguió los preceptos familiares. Ya hemos repasado las ideas que Wollstonecraft expone en Vindicación de los derechos de la mujer (1791), ahora, veamos como las plasma Austen en sus novelas.

En un momento en que se considera que a las mujeres se les debe educar para la vida doméstica, ambas mujeres se lanzan a la aventura de la escritura. Una actividad complicada de desarrollar para las mujeres de la época porque no se les educaba "como a los hombres» para poder desarrollar actividades intelectuales. A pesar de todo, parece que las circunstancias estén cambiando y un número incipiente de escritoras irrumpen en el espacio editorial. Las causas: el fin del mecenazgo permite no firmar las obras, por ejemplo Austen utiliza el seudónimo By a Lady; algunas asociaciones son un buen ejemplo para unas autoras huérfanas de modelos; y el auge del empirismo científico junto a los sentimientos individuales.

Las protagonistas de ambas teorías son las mismas. Wollstonecraft cuando habla de mujeres habla de las mujeres de la clase social que conoce, aquellas pertenecientes a una clase acomodada, educada para el matrimonio y que se ve en serias dificultades si pierde su oportunidad de formar su propia familia. Austen tiene un agudo sentido de la observación y lo utiliza para describir la vida de las mujeres de la pequeña aristocracia rural y la incipiente burguesía. Estas mujeres tenían un espacio muy reducido de actuación: sus casas, su vida familiar, los bailes, las visitas a familiares $y$ vecinos $y$, sobre todo, el matrimonio. Aunque tratemos a ambas autoras como rebeldes lo cierto es que la ficción que cultivaba Austen era mejor aceptada, pues no se veía la ironía ni la perspicacia de los textos y se quedaban con la historia más emotiva y romántica. Sin 
olvidar que el excelente trabajo realizado por la escritora permite ocultar sus ideas detrás de un aparente convencionalismo. Wollstonecraft fue más atrevida al introducirse en el ámbito de la escritura política con Vindicación de los derechos de la mujer, donde hace una determinada defensa de lo que se veía claramente como una postura política en la que trataba temas como la educación, el derecho de elección, la familia...

Centrándonos en Orgullo y prejuicio (1813 [2009]) podemos afirmar que nos presenta de manera brillante el escenario en el que se desarrolla la vida cotidiana y describe perfectamente el modo de vida de esa aristocracia que depende de las rentas para la subsistencia: su cotidianidad, sus vacaciones, sus necesidades, sus deseos y sus aspiraciones... Traza un perfecto marco histórico que nos acerca cómo era la vida de aquellas personas, sobre todo, la vida de aquellas mujeres. La única licencia de la escritora son sus finales felices.

Uno de los aspectos más interesantes de sus novelas son sus protagonistas (Elizabeth Bennet, en nuestro caso, Anne Elliot en Persuasión (1817), Emma, en la novela del mismo nombre, entre otras). En ninguno de estos casos nos encontramos con mujeres sumisas que se pliegan a las normas sociales sin cuestionamiento. Se trata de personajes que abren la puerta a modelos de conducta diferentes a los que se establecen a finales del XVIII y principios del XIX, sería la mujer que Wollstoncraft busca con sus propuestas de cambio en la sociedad. Elizabeth es una mujer culta, tiene a su disposición una gran biblioteca, además es una mujer con autoestima, orgullo y dignidad. No tiene miedo a enfrentarse a los varones de su entorno. El intercambio verbal con Darcy, el protagonista masculino, así lo demuestra, pero también la discusión con su padre cuando le culpa de lo ocurrido con hermana Lydia (se fuga con el oficial Wickham).

Elizabeth no se muerde la lengua y expone sus opiniones en público sin ningún pudor. Incluso se atreve a burlarse de alguien de clase social superior. En el episodio con la señorita Bingley, que reproducimos a continuación, se puede comprobar la diferencia en la consideración, la protagonista se atreve a transgredir normas que la menor de los Bingley no se atrevería ni a cuestionar en voz baja.

- iQué horror! -gritó la señorita Bingley. Nunca he escuchado nada tan abominable ¿Cómo podríamos darle su merecido?

- Nada más fácil, si estás dispuesta a ello -dijo Elizabeth. Todos sabemos fastidiar y mortificar unos a otros. Búrlese, ríase de él. Siendo tan íntima amiga suya, sabrá muy bien cómo hacerlo.

- No sé, le doy mi palabra. Le aseguro que mi gran amistad con él no me ha enseñado cuáles son sus puntos débiles. ¡Burlarse de una persona flemática, de tanta sangre fría! Y en cuanto a reírnos de él sin más ni más, no debemos exponernos; podría desafiarnos y tendríamos nosotras las de perder.

- iQue no podemos reírnos del señor Darcy! -exclamó Elizabeth. Es un privilegio muy extraño, y espero que siga siendo extraño, no me gustaría tener muchos conocidos así. Me encanta reírme.

- La señorita Bingley - respondió Darcy- me ha dado más importancia de la que merezco. El más sabio y mejor de los hombres o la más sabia y mejor de las 
acciones, pueden ser ridículos a los ojos de una persona que no piensa en esta vida más que en reírse.

- Estoy de acuerdo -respondió Elizabeth-, hay gente así, pero creo que yo no estoy entre ellos. Espero que nunca llegue a ridiculizar lo que es bueno o sabio. Las insensateces, las tonterías, los caprichos y las inconveniencias son las cosas que realmente me divierte, lo confieso, y me río de ellas siempre que puedo. Pero supongo que éstas son las cosas de las que usted carece.

- Quizá no sea posible para nadie, pero yo he pasado la vida esforzándome para evitar estas debilidades que exponen al ridículo a cualquier persona inteligente. - Como la vanidad y el orgullo, por ejemplo.

- Sí, en efecto, la vanidad es un defecto. Pero el orgullo, en caso de personas de inteligencia superior, creo que es válido. Elizabeth tuvo que volverse para disimular una sonrisa. (Austen, 1813 [2009]: 116-117).

La actividad natural de cualquier mujer era el matrimonio, pero la protagonista de Austen no piensa casarse (sabiendo las dificultades que tendrá cuando falte su padre) sino es con amor. En ese sentido se muestra intransigente lo que confiere al personaje gran independencia. En cierto modo podemos reconocer a la escritora en estas heroínas. Todos estos rasgos son propios. Recordemos la negativa de Elizabeth a casarse con el señor Collins.

- Va usted demasiado deprisa -exclamó Elizabeth. Olvida que no le he contestado. Déjeme que lo haga sin más rodeos. Le agradezco su atención y el honor que su proposición significa, pero no puedo menos que rechazarla.

- Sé de sobra -replicó Collins con un grave gesto de su mano- que entre las jóvenes es muy corriente rechazar las proposiciones del hombre a quien, en el fondo, piensa aceptar, cuando pide su preferencia por primera vez, y que la negativa se repite una segunda o incluso una tercera. Por esto no me descorazona en absoluto lo que acaba de decirme, y espero llevarla al altar dentro de poco.

- ¡Caramba, señor! -exclamó Elizabeth. ¡No sé qué esperanzas le pueden quedar después de mi contestación! Le aseguro que no soy de las mujeres, si es que tales mujeres existen, tan temerarias que arriesgan su felicidad al azar de que las soliciten una segunda vez. Mi negativa es muy en serio. (Austen, 1813 [2009]: 162-163).

Pensemos en los ejes básicos en los que Wollstonecraft desarrolla su análisis de la situación de las mujeres: educación, diferenciación sexual, falta de espacio propio, familia y legislación.

Elizabeth sí se muestra una mujer racional y con educación, tiene capacidad para conversar, responder a las agresiones y humillaciones verbales... Sus hermanas son diferentes. Ni Jane, ni Lydia, ni Kitty muestran esa inclinación por la instrucción, la única que parece estar ávida de conocimientos es Mary (porque no es guapa), pero su falta de ingenio la convierten en algo intransigente.

Por otra parte, vemos en la señora Bennet el ejemplo perfecto de mujer criada en los salones donde la competencia por obtener un buen marido es la única finalidad para las jóvenes que están allí, como describe Wollstonecraft. Siempre que habla de la belleza de sus hijas y las cualidades que tienen, nunca señala la inteligencia como uno de ellos. Es incapaz de relacionarse con su marido. Éste es un hombre más bien 
racional y a ella no la han educado para ello. Es precisamente lo que se expone en Vindicación de los derechos de las mujeres, la instrucción de las jóvenes permitiría a éstas ser mejores madres y esposas porque estarían al mismo nivel que sus compañeros, no aparecería ese resentimiento latente entre ambos, el marido porque la considera insufrible y ella porque no lo entiende.

En el caso de los espacios están muy bien delimitados. El único que tiene un lugar que puede considerar suyo es el señor Bennet que se pasa el día en su estudio y si alguien entra se molesta mucho. Las mujeres de la familia están todas juntas en la sala cada una haciendo una actividad, lo más normal es que cosan, lean o estén descansando ociosamente. Es difícil en este ambiente poder desarrollarse como individuo.

La institución familiar es el centro de toda la obra. De hecho, cuenta la historia de la familia Bennet a lo largo de un año. En ella, los papeles están cuidadosamente definidos. El padre que es el propietario de la tierra es el proveedor, la madre tiene hijo está en negrita adrede?s (si son niñas como en este caso es un problema como ya hemos comentado) y educa a sus hijas e hijos. En el caso de los Bingley no hay padres vivos, pero el concepto de familia se entiende del mismo modo, un proveedor varón (Charles Bingley y el señor Hurst) y unas mujeres dependientes (la señorita Bingley y la señora Hurst). El patrón de conducta que hemos desgranada con anterioridad se repite aquí. Será la pequeña de los Bingley la que intente demostrar sus cualidades dejando en mal lugar al resto de las mujeres Bennet para ganarse el favor de Darcy.

Para finalizar, pensemos en el aspecto legislativo. La herencia pasa de varón a varón de la familia lo que excluye a las mujeres del derecho de propiedad. Esto hace que no puedan adoptar una actitud crítica, pues supondría poner en riesgo su subsistencia. Sólo, aquellas mujeres que, por cualquier razón, tienen fortuna (viudas con solvencia) pueden imponer sus deseos. Lady Catherine de Bourgh, tía del protagonista, es el ejemplo.

Otro aspecto que dificulta el desarrollo de las mujeres es la exigencia de dote. El hecho de que las mujeres deban aportar al matrimonio una cantidad para poder mantenerse, sin ser una carga para el marido, las coloca en una postura muy complicada cuando no la tiene. Austen critica esta situación en boca de la señora Bennet, que se queja de esta situación diciendo: «Nunca podré dar gracias por nada que se refiera al legado. No entenderé jamás que alguien pueda tener la conciencia tranquila desheredando a sus propias hijas». (Austen, 1813 [2009]: 184) Mientras la reivindicación continúa más delante cuando Lady Catherine se muestra partidaria de mantener la herencia dentro de la misma línea familiar independientemente del sexo de la heredera o el heredero (ella tiene una única hija):

Tengo entendido que la propiedad de su padre debe heredarla el señor Collins. Lo celebro por usted -dijo volviéndose hacia Charlotte-; pero no veo motivo para legar las posesiones fuera de la línea familiar. En la familia de sir Lewis Bourgh no se hizo así. (Austen, 1813 [2009]). 
Después de todo lo expuesto $y$, a pesar de que algunas pensadoras consideran que es aventurado hablar de reivindicación de la igualdad (precursoras del feminismo) en relación con estas autoras, porque la educación la ligaban al hecho de ser mejores madres y esposas (compañeras de sus maridos), lo cierto es que debemos tener en cuenta los límites que la sociedad de principios del XIX plantea. Austen plantea una nueva feminidad que surge de manera incipiente en la literatura, pero que no tardará en aparecer en otros ámbitos de la sociedad, se está gestando el primer feminismo (sufragismo).

\section{El presente es cosa de mujeres}

Temporalmente, El diario de Bridget Jones (1996 [1999]) coincide con la denominada tercera ola del feminismo, no porque las diferentes etapas del feminismo se sucedan en el tiempo sino porque a partir de los 90 aparece una nueva forma de conceptualización del feminismo. La teoría feminista empieza a considerar que el movimiento no es monolítico, sino que debe hablarse de feminismos porque la realidad de las mujeres es diversa y se deben de incluir todas ellas en los procesos de teorización, desarrollo y acción. No es lo mismo ser mujer en el primer que en el tercer mundo, tampoco es igual ser una mujer atea que una mujer religiosa ( $y$ no todas las religiones colocan en la misma posición a sus mujeres), la clase social a la que se pertenece también resulta determinante para definirse. Estos movimientos responden a cuestiones antiguas como la pobreza, la discriminación, la marginación, la educación, la violencia de género, los abusos sexuales... actualizándolas, al mismo tiempo que plantean nuevas reivindicaciones. A partir de ahora dejaremos de hablar de feminismo en singular para tratar los feminismos. Cada uno de ellos con sus agendas, ninguna más importante que la otra.

Después de dibujar este marco general, nos planteamos la cuestión de si la obra de Fielding se desarrolla dentro de los parámetros de estas teorías feministas. Lo cierto es que definir como feminista el texto de Helen Fielding es una cuestión a debate, sin embargo, algunos de los temas centrales de El diario de Bridget Jones (1996 [1999]) aparecen en las agendas de los movimientos feministas. A continuación, comprobaremos si la escritora británica contemporánea hace el mismo esfuerzo que su antecesora por deconstruir los estereotipos femeninos.

La chick lit es un género literario que se caracteriza por el humor y esta protagonizado por una mujer profesional y sofisticada (aunque Bridget no lo parece) tiene problemas con sus parejas porque estos suelen huir del compromiso, sólo una de sus parejas estará dispuesta a comprometerse (representará un modelo masculino diferente que no desarrollaremos en este artículo). Otro aspecto interesante de estas novelas es que contra la creencia de que las mujeres entre ellas son crueles, todas tienen un grupo de amigas que le hacen de apoyo (puede 
haber un amigo gay en el equipo $\left.{ }^{1}\right)$. Hablan de sexo, las frustraciones amorosas y los problemas profesionales. También es cierto que hay una mujer en su entorno que parece que tiene todo lo que ella desea y la mira con recelo y envidia, pero nunca será la competencia que sí se observa en Orgullo y prejuicio (1813 [2009]) entre las jóvenes casaderas. Las conversaciones suelen producirse en el pub donde surgen una serie de despiadados comentarios del resto de clientes como sucedía en los bailes de la obra de Austen.

Elizabeth y Bridget son personajes femeninos que llevan a cabo una búsqueda de su propio ser a lo largo de la historia en la que van autoafirmándose como mujeres y como seres humanos. En este proceso los confidentes son muy importantes: Jane y la señora Gardimer, en el caso de la primera, y Tom, Sharon y Jude, en el segundo.

En cuanto a los temas que propiamente pertenecen a las agendas feministas, encontramos que la división sexual del trabajo y la segregación de espacios que hemos podido observar en la novela de Austen están todavía vigentes en la obra de Fielding. Si nos fijamos en el personaje de Pam Jones, la madre de Bridget, veremos que ha sido ama de casa. La señora Jones se encargaba del trabajo no remunerado dentro del hogar: limpia, cuida, alimenta... El incidente con el funcionario de la oficina de impuestos, pone en valor el trabajo callado que durante años ha realizado: "Escuche, ¿sabe, usted, hacer un asado?». Este episodio pone de manifiesto de forma muy didáctica la aportación de las mujeres a la economía, la invisibilización de su tarea. La mayoría de los movimientos feministas tienen en su agenda la reformulación del concepto trabajo y, sobre todo, reconocer el valor del trabajo de cuidado que, tradicionalmente, han desarrollado las mujeres. Incluso se hacen cálculos de la repercusión que éste tiene en el Producto Interior Bruto (PIB) de un país.

Es interesante señalar también que la señora Jones sufre el síndrome del nido vacío. Una crisis existencial que se produce cuando esa ama de casa que ronda los cincuenta y que ha dedicado su vida al cuidado de la familia se queda sin familia que cuidar. La relación con su marido se ha instalado en la rutina y no se siente necesitada. Ella quiere sexo y atención porque todavía se siente vital y con energía, pero ya no tiene en qué volcarla con las hijas/hijos independizados. Al final, consigue un trabajo remunerado fuera de casa. Además, Pamela rompe uno de los tabús más arraigados, la sexualidad de las personas maduras. Al igual que se trata la educación sexual en la infancia y adolescencia, se convierte en fundamental promover una vida sexual sana en personas de más edad.

Una de las obsesiones de Bridget es su peso. Anota en su diario cada caloría que come y cada gramo que aumenta o pierde. El trabajo del cuerpo de las mujeres es uno de los elementos más interesantes de la

${ }^{1}$ Los movimientos feministas actuales se comprometen más allá de la defensa de los derechos de las mujeres y colaboran con la reivindicación de la igualdad y la equidad para otros colectivos marginados y minorizados. La teoría queer anda de la mano con ese nuevo feminismo en muchos casos e introducir un amigo y confidente homosexual en el grupo de amistades de estos personajes apunta a esta idea. 
novela. Los cuerpos femeninos se han repensado siempre, desde un punto de vista masculino. Por ejemplo, en medicina el paciente estándar es un hombre blanco de metro ochenta y noventa kilos, las particularidades físicas y biológicas de las mujeres que influyen en el diagnóstico y el tratamiento no se tienen en cuenta.

Naomi Wolf trata este tema señalando la imposición de unos modelos inalcanzables. Esos estereotipos son precisamente los que quiere alcanzar Bridget. Una imagen que surge en la sociedad de la información y la comunicación de los medios, el Cosmopolitan es casi una Biblia. El ideal no es la mujer "humana» anterior, es decir, aquella que por naturaleza presenta las condiciones biológicas perfectas para su labor como mujer (reproducción). La industria de la belleza nos muestra unos modelos artificiales que pasan a ver entendidos como los «naturales». Los movimientos feministas trabajan para que las mujeres estén contentas con sus cuerpos cuidándolos y admirándolos para ellas mismas. La inseguridad manifiesta de Bridget respecto a su cuerpo tiene que ser leída en clave de parodia. Muestra, por una parte, preocupación por ser una persona con la que no se identifica. Por otra parte, cuando se arregla para presentarse ante su compañero (Daniel Cleaver) se da cuenta de que para los hombres no es tan importante la apariencia física. También se puede hacer un aprendizaje vicario, de este episodio, al comprobar que cuanto más contenta está con ella misma, más feliz es, le salgan bien o mal las cosas que planea.

Bridget está en constante transformación, cada acontecimiento (positivo o negativo) de su vida supone crecimiento y desarrollo. En este sentido, queremos llamar la atención sobre el hecho de que las sociedades patriarcales se utilizan todo tipo de estrategias para utilizar, dominar y crear dependencia en el cuerpo femenino, pero puede subvertirse este binomio si entendemos que el modelo corporal tiene un carácter temporal que depende de aspectos culturales, por lo tanto, debemos realizar una constante reformulación del Yo.

Otro de los temas estrella de las agendas feministas casi desde el principio del movimiento es la maternidad y relacionado con ella el matrimonio. La posibilidad de decidir sobre su estado civil y el momento y el número de hijas/hijos es una reivindicación histórica del movimiento de liberación de la mujer. En El diario de Bridget Jones (1996 [1999]) la protagonista transita entre el espacio de la soltería y del matrimonio gracias a sus amistades. Magda es madre y esposa. Ha dejado su trabajo para dedicarse a su familia, pero no está satisfecha y aconseja a la protagonista que continúe así [soltera]. Sin embargo, no es fácil encajar en un mundo construido para los matrimonios.

Quiero a Magda y Jeremy. Algunas veces me quedo en su casa, admirando las sábanas frescas y los numerosos tarros de cristal llenos de diferentes tipos de pasta e imaginando que ellos son mis padres. Pero, cuando están juntos con sus 
amigos casados, siento como si me hubiera convertido en Miss Havisham. ${ }^{2}$ (Fielding, 1996 [1999], 46).

La incomprensión rodea a la protagonista en el «mundo de los "Petulantes" Casados». Bridget se da cuenta en una cena con parejas casadas donde es objeto de mofas que rozan el insulto.

Sí, ¿por qué no te has casado todavía, Bridget? - dijo Woney con desdén [...] Deberías darte prisa y explotar tus encantos, sabes, viejarrona -dijo Cosmo, tragando medio cuarto de litro de Pauillac del 82. El tiempo se te acaba. (Fielding, 1996 [1999]).

Bridget no es una solterona, es una mujer soltera, aunque la presión social es muy fuerte y sobreponerse a ella siempre es una victoria. Otro de los temas principales de las agendas de los movimientos feministas es la violencia contra las mujeres. Bridget sufre acoso sexual en su vida profesional y personal. En el primer trabajo mantiene una relación consentida con su jefe, el seductor Daniel Cleaver. Se inicia con un intercambio de correos electrónicos subidos de tono y acaba cuando la joven se da cuenta que le está engañando. En la cadena de televisión su jefe realiza continuos avances buscando ese contacto sexual del que ella se zafa intentando conservar la dignidad y el trabajo.

Resulta evidente que Fielding no está haciendo apología del acoso. Con estos ejemplos, planteados de manera muy sutil y atravesados por ese sentido del humor tan especial que la caracteriza está colocando una señal de alerta para las lectoras. También es una llamada de atención a los lectores que pueden verse reflejados y entender qué sienten las mujeres en esa situación.

\section{Elizabeth y Bridget: dos heroínas construyendo modelos}

El planteamiento de partida del estudio era que las teorías feministas se habían introducido en la literatura de ficción facilitando modelos alternativos a las mujeres. Desde esta afirmación intentábamos encontrar a heroínas que llevaran a cabo esta tarea de resistencia feminista. Los dos personajes escogidos son: Elizabeth Bennet y Bridget Jones.

El resultado confirma la hipótesis inicial ya que hemos observado el modo en que Jane Austen y Helen Fielding construyen personajes que responden a las estructuras patriarcales de la sociedad en la que viven.

El personaje de Orgullo y prejuicio (1813 [2009]) adopta una postura activa en una sociedad que relega a las mujeres a la inactividad y la pasividad. Elizabeth es una mujer inteligente, capaz de exponer y defender sus opiniones cuando se suponía que las mujeres no tenían capacidad de raciocinio.

${ }^{2}$ Miss Havisham es un personaje de la obra de Charles Dickens Great Expectations (Grandes esperanzas, 1861). Una mujer de edad y soltera que vive en una mansión arruinada con su hija adoptiva y es considerada como una bruja. 
Esta primera ruptura con las normas sociales de la época se ve reforzada cuando niega su interés por un matrimonio de conveniencia y se obstina en conseguir un matrimonio por amor.

Pero toda su determinación, dignidad y orgullo no le impide mostrarle honesta u reconocer sus errores. Se comporta de un modo que se supone no es propio de las mujeres frívolas, manipuladoras, poco inteligentes y emocionales. Es decir, rompe con la creencia de que las mujeres están próximas a la naturaleza en contraposición al varón que tendría una actitud más lógica.

La protagonista se presenta como un nuevo tipo de mujer. Pero si puede hacerlo es porque ha recibido instrucción. Algo que estaba vetado a la mayoría de las mujeres de la época, educadas para ser esposas y madres. Una de las exigencias de protofeministas como Mary Wollstonecraft reivindica en su obra.

Bridget Jones, por otro lado, es una mujer contemporánea con todos los problemas, necesidades, miedos, frustraciones, valores, autonomía, éxito... Los movimientos feministas han conseguido que tenga derechos en el plano legal (voto, trabajo fuera de casa, capacidad de elección...). Es el ejemplo de mujer empoderada. Pero, al mismo tiempo, tiene que enfrentarse al peso de la tradición y las expectativas sociales que incluyen el matrimonio heterosexual y la descendencia.

A pesar de todo, la joven secretaria y presentadora de televisión avanza repensando constantemente su proyecto de vida y aprendiendo día a día a vivir como quiere. Defender el caso de Bridget como modelo feminista resulta complicado por el gran número de prejuicios y malos entendidos que surgen entorno al feminismo. Aun así, podemos afirmar que toma decisiones sobre su cuerpo, su vida, se reinventa de forma continuada... La vida sexual activa, el trabajo remunerado y una vida independiente ya no son suficientes e incluye en su proyecto vital un hombre que Fielding construye como un hombre nuevo que entiende la autonomía de su compañera.

Por lo tanto, podemos concluir que Austen en sus relatos desarrolla heroínas que rompen estereotipos basados en las desiguales entre mujeres y hombres mientras que Fielding avanza en modelos hacia una convivencia cada vez más igualitaria acercándose a algunas de las premisas de las agendas feministas contemporáneas. En ambos casos sus personajes se muestran como ejemplos para las mujeres de las sociedades en las que nacen.

\section{Bibliografía}

BeltRÁn, ElenA (1994): «Público y privado: sobre feministas y liberales: argumentos en un debate acerca de los límites de lo político», Doxa, 1516, Madrid.

BenHABIB, Seyla (2006): El ser y el otro en la ética contemporánea: feminismo, comunitarismo y posmodernismo, Gedisa, Barcelona. 
Benhabib, Seyla y Cornell, Drucilla (1999): «Más allá de la política de género", en BeNHABIB, SeYla y CORNeLl, DruCILla (EDS.) (1997): Teoría Feminista y Teoría Crítica, Edicions Alfons el Magnànim, València.

Campillo, Neus (2004): "Feminismo, Ciudadanía y Cultura Crítica», Recerca, 4, Departament de Filosofia i Sociologia, Universitat Jaume I, Castelló.

CORTINA, Adela (2008): La Escuela de Francfort. Crítica y utopía, Síntesis, Madrid.

De Aranzazu, María (2002): «Observaciones a la Teoría de la Acción Comunicativa de Habermas desde una Óptica Feminista», Universidad de Zaragoza y Universidad Diego Portales, Chile.

FASCIOLI, ANA (2010): "Ética del cuidado y ética de la justicia», 12, Revista ACTIO, Facultad de Humanidades y Ciencias de la Educación de la Universidad de la República de Uruguay.

FRASER, NANCY (1990): “¿Qué tiene de crítica la teoría crítica? Habermas y la cuestión del género», en BENHABIB, SEYLA y CoRNelL, Drucilla (eds.) (1990): Teoría feminista y teoría crítica: ensayos sobre la política de género en las sociedades del capitalismo tardío, Edicions Alfons el Magnànim, Institució Valenciana d'Estudis i Investigació, València.

FraSer, NANCy y HONNeTH, AXel (2006) ¿Redistribución o reconocimiento?, Madrid, Morata.

GarcíA-MarzÁ, Domingo (1992): Ética de la justicia. J. Habermas y la ética discursiva, Tecnos, Madrid.

GilligAN, CAROL (1985): «La moral y la teoría. Psicología del desarrollo femenino», Fondo de Cultura Económica, México.

GILLIGAN, CAROL (2006): «Con otra voz: las concepciones femeninas del yo y de la moralidad», en LÓPEZ DE LA VIEJA, M. TERESA (coord.) (2006): Bioética y Feminismo: estudios multidisciplinares de género, Universidad de Salamanca.

Guerra, María José (1999): «Mujer, identidad y espacio público», Contrastes, vol. IV, Universidad de Málaga.

GUIRAO, CRISTINA (2010): «Modernidad y Postmodernidad en el feminismo contemporáneo", Feminismo/s, 15, Universidad de Alicante.

HABERMAS, Jürgen (1986): Ciencia y técnica como ideología, Tecnos, Madrid.

HABERMAS, JÜRGEN (1991): Conciencia moral y acción comunicativa, Edicions 62, Barcelona.

HABERMAS, JÜRGEN (1999): «El vínculo interno entre Estado de Derecho y Democracia» en HABERMAS, JÜRGEN (1999): La inclusión del otro: estudios de teoría política, Paidós, Barcelona. 
Habermas, Jürgen (2000): Aclaraciones a la ética del discurso, Trotta, Madrid.

HABERMAS, JÜRGEN (2006): «Espacio público y esfera pública política. Raíces biográficas de los motivos intelectuales» en HABERMAS, JÜRGEN (2006): Entre naturalismo y religión, Paidós, Barcelona.

MARín, GLORIA (1993): «Ética de la justicia, Ética del cuidado. Por qué este debate?», Universitat de Girona.

Millán, MARCo ANTONIO (2006): "Sistema y mundo de la vida en la acción comunicativa», Anuario de Investigación de la Comunicación CONEICC XIII, Universidad Anáhuac, México.

Pateman, Carole (1990): «Críticas feministas a la dicotomía público/privado», en CASTells, CARME (Comp.) (1996): Perspectivas feministas en teoría política, Paidós, Barcelona.

Pateman, Carole (1995): "Hacer un contrato», en Carole Pateman: El contrato sexual, Anthropos, Barcelona.

PUleE, Alicia (2005): "Lo personal es político», en Amorós, Celia y Ana de Miguel, eds. (2005): Teoría Feminista: de la Ilustración a la globalización (vol.2), Minerva Ediciones, Madrid.

REVERTER, SONIA (2003): "La perspectiva de género en la filosofía», Feminismo/s, Revista de Investigación Feminista, Universidad de Alicante.

REVERTER, SONIA (2008): "Mujeres contra el Estado», en ReVERTER BAÑón, SONIA y CABAllero, JunCal (eds.) (2008): Dones contra l'Estat, Universitat Jaume I, Castelló de La Plana.

SCOTT, JOAN W. (1996): «El género: una categoría útil para el análisis histórico", LAMAS, MARTA (Compiladora): El género: la construcción cultural de la diferencia sexual, PUEG, México. 
